\title{
DEFORMATION BEHAVIOR OF WELDED STEEL SANDWICH PANELS UNDER QUASI-STATIC LOADING
}

\author{
Michael E. Carolan \\ David Y. Jeong \\ A. Benjamin Perlman \\ Yim H. Tang \\ Volpe National Transportation Systems Center \\ Research and Innovative Technology Administration \\ US Department of Transportation \\ Cambridge, MA, USA
}

\author{
Francisco González III \\ Federal Railroad Administration \\ US Department of Transportation \\ Washington, DC, USA
}

\begin{abstract}
For the past two decades, the Federal Railroad Administration (FRA) Office of Research and Development has sponsored research conducted by the Volpe National Transportation Systems Center (Volpe Center) in safety matters related to the transportation of hazardous materials by railroad tank cars. Recent research conducted by the Volpe Center has included the application of semi-empirical and computational (i.e., finite element analysis) methods to estimate the puncture resistance of conventional railroad tank cars under generalized head and shell impact scenarios. Subsequent work identified sandwich structures as a potential technology to improve the puncture resistance of the commodity-carrying tank under impact loading conditions.
\end{abstract}

This paper summarizes basic research (i.e., testing and analysis) conducted to examine the deformation behavior of flat-welded steel sandwich panels under two types of quasi-static loading: (1) uniaxial compression; and (2) bending through an indenter. The objectives of these tests were to: (1) confirm the analytical and computational (i.e., finite element) modeling of sandwich structures, (2) examine the fabrication issues associated with such structures (e.g., material selection and welding processes), and (3) observe the deformation behavior and local collapse mechanisms under the two different types of loading. In addition, the uniaxial compression tests were performed to rank or screen different core geometries. Five core geometries were examined in the compression tests: pipe or tubular cores with outer diameters equal to 2,3 , and 5 inches; a 2-inch square diamond core; and a double-corrugated core called an X-core with a 5-inch core height.

The compression tests showed excellent repeatability of structural (i.e., force-crush) response for panels with similar cores and welding. The 3-inch pipe core and the diamond core were selected as candidate cores for the next test series because they possess attributes of moderate strength and moderate relative density. In addition, force-crush curves calculated from finite element analysis were in reasonable agreement with the measured curves for all cores.

Bend tests using a 12-inch by 12-inch indenter with 1-inch radius rounded edges were also conducted. The panels were simply-supported over 4-inch diameter rollers spanning 24 inches between the centers of the rollers. The bend tests included three variables: (1) core type (diamond core and 3inch pipe core); (2) core orientation relative to the supports (cores running either parallel or perpendicular to the rollers used to support the panels); and (3) face sheet type (solid plates on both sides, strips used as face sheets on both sides, and a combination of solid plates and strips. Finite element analysis of the bend tests produced nearly identical shapes to the measured force-displacement curves.

\section{INTRODUCTION}

Previous work has identified a number of potential strategies for improving the crashworthiness performance of tank cars involved in impacts due to collisions and/or derailments [1]. One of the tools that can be used to implement these strategies is the engineered metal sandwich structure [2]. A series of tests was developed to better understand the behavior of sandwich panels under compression and bending loads, examine the effects of core geometries on panel deformation behavior, and assist in the selection of desirable panel attributes for service as tank car protective structures.

As discussed in previous publications, limited space exists between the outside of an existing tank car and the boundary of 
the AAR limiting outline for interchange service [1]. This space constraint limits the technologies that can be installed exterior to the tank shell for the purpose of absorbing collision energy. However, the tank itself possesses significant energyabsorbing capacity through plastic deformation and sloshing of the commodity within the tank. Puncture of the tank has been observed to occur around the impacting object's perimeter in both tests and analyses [5]. The tank's energy-absorbing ability can be taken advantage of if this localized puncture can be delayed during an impact event. Because a larger impacting object loads a larger area of tank, more energy is required to puncture a tank as the loaded area is increased [5, 3].

The sandwich panel is one technology that is capable of this blunting effect. When an impacting object strikes the sandwich panel, the panel deforms in such a way as to present the tank with a larger impacting object. From finite element analyses, the blunting advantages of the sandwich panel are seemingly lost when fracture of either facesheet or core initiates. The initiation of fracture within the panel is generally followed by progressive failure of the panel and the underlying tank. Because of the competing needs for a flexible panel that conforms to an impacting object but a tough panel that resists tearing, testing was utilized to examine the benefits and disadvantages of various panel designs.

\section{TEST 1 - UNIAXIAL COMPRESSION}

Uniaxial compression tests were performed in May of 2009 using facilities at Lehigh University. Specifically, the 5-million pound capacity universal testing machine at Fritz Laboratory was utilized for this testing series. This test was designed to measure the force versus displacement behavior of sandwich panels when subjected to a uniform loading across their whole facesheets. Because this test loaded both the top and bottom facesheets uniformly, this test emphasized core behavior rather than facesheet behavior. This test series was also used to determine the mode shapes of the panels as they crushed, as well as compare manufacturing techniques used in the assembly of the panels.

\section{Panel Design}

Three basic core shapes were examined in this test: round (tube) cores, square (diamond) cores, and X-cores. For the tube cores, tubes of three diameters were used for the panels: 2-inch outer diameter, 3-inch outer diameter, and 5-inch outer diameter. The square tubes measured approximately 2 inches on a side, for a core height of 2.6 inches with the tubes rotated 45 degrees. The X-cores had a height of 5 inches. For all cores, the core thickness was approximately 0.125 inches. The three core shapes are shown in Figure 1.

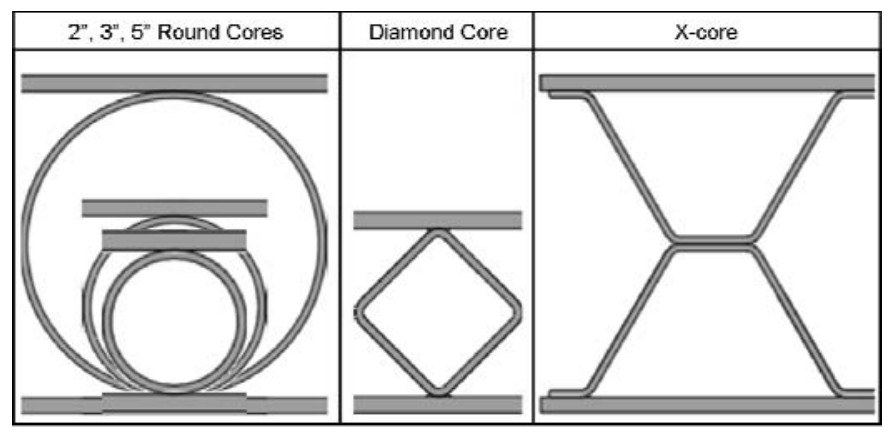

Figure 1. Schematic View of Three Core Geometries

For each of the cores tested, the influence of material properties was desired to be minimized. For this reason, AISI 1010 was selected for use as the core material on the basis of its availability in all core configurations that were to be tested. Because the loads were being applied across the entire surface of the facesheet, the selection of facesheet material was not critical to the success of this test. ST100XF Domex steel was selected for the facesheets. This material is a high-yield steel that is typically used in structural applications.

Stress-strain and elongation data were measured for each of the materials used in this test. Five samples of each material were tested. The average results for each material are reported in Table 1.

Table 1. Material Properties

\begin{tabular}{|c|c|c|c|}
\hline Material & $\begin{array}{c}\text { Yield } \\
\text { Stress } \\
\mathbf{( k s i )}\end{array}$ & $\begin{array}{c}\text { Ultimate Stress } \\
\mathbf{( k s i )}\end{array}$ & \% Elongation \\
\hline Domex Plate & 101.2 & 113.2 & 17.8 \\
\hline 2 inch diamond 1010 & 60.5 & 71.4 & 21.9 \\
\hline 2 inch round 1010 & 52.3 & 62.6 & 32.2 \\
\hline 3 inch round 1010 & 43.0 & 53.6 & 35.5 \\
\hline 5 inch round 1010 & 37.1 & 51.8 & 38.7 \\
\hline
\end{tabular}

This material data was used in the finite element modeling for both the compression and bending test series. Finite element analysis was performed using Abaqus/Explicit, a commercial, general-purpose finite element analysis software package [6]. Non-linear elastic-plastic material behavior was modeled using an isotropic hardening behavior to describe the materials once yield had been exceeded.

A total of fourteen panels were fabricated for the first series of tests. The panels were all six inches deep by $24-27$ inches in width. The width varied based upon the number of cores in the particular panel. Core-to-facesheet welding was performed either manually or robotically for each panel. Duplicate panels of the same geometry were fabricated either with manual welding or robotic welding to allow for comparison of the two fabrication techniques. A description of the test articles is provided in Table 2 . 
Table 2. Test Articles for Compression Test

\begin{tabular}{|c|c|c|c|}
\hline $\begin{array}{c}\text { Panel } \\
\text { No. }\end{array}$ & $\begin{array}{c}\text { Core } \\
\text { Material }\end{array}$ & $\begin{array}{c}\text { Weight } \\
\text { (lbs) }\end{array}$ & Fabrication Method \\
\hline $0047-01$ & 5" round pipe & 36.5 & Slot/skip (manual) \\
\hline $0047-02$ & 5" round pipe & 36.4 & Slot/skip (robotic) \\
\hline $0047-03$ & 3" round pipe & 33.9 & Slot/skip (manual) \\
\hline $0047-04$ & 3" round pipe & 33.8 & Slot/skip (robotic) \\
\hline $0047-05$ & 2" round pipe & 34.3 & Slot/skip (manual) \\
\hline $0047-06$ & 2" round pipe & 34.3 & Slot/skip (robotic) \\
\hline $0047-07$ & 2" round pipe & 34.2 & $\begin{array}{c}\text { Slot/skip, stitch between cores } \\
\text { (manual) }\end{array}$ \\
\hline $0047-08$ & 2" round pipe & 34.3 & $\begin{array}{c}\text { Slot/skip, stitch between cores } \\
\text { (robotic) }\end{array}$ \\
\hline $0047-09$ & 5" X-core & 40 & Spot (manual) \\
\hline $0047-10$ & 5" X-core & 40 & Spot (manual) \\
\hline $0047-11$ & 5" X-core & 40 & Slot \& spot (manual) \\
\hline $0047-12$ & 5" X-core & 40 & Slot \& spot (robotic) \\
\hline $0047-13$ & 2" square & 33.1 & Slot/skip (robotic) \\
\hline $0047-14$ & $\begin{array}{c}\text { 2" square } \\
\text { pipe }\end{array}$ & 33.4 & $\begin{array}{r}\text { Slot/skip, stitch between cores } \\
\text { (robotic) }\end{array}$ \\
\hline
\end{tabular}

\section{Test Setup and Results}

Panels were placed on a flat block in the universal testing machine. The movable test head was positioned slightly above the support block at the top of the test article and progressed downward at a target speed of 0.2 inches per minute. This speed was chosen as sufficiently slow to prevent the introduction of dynamic effects into the test results.

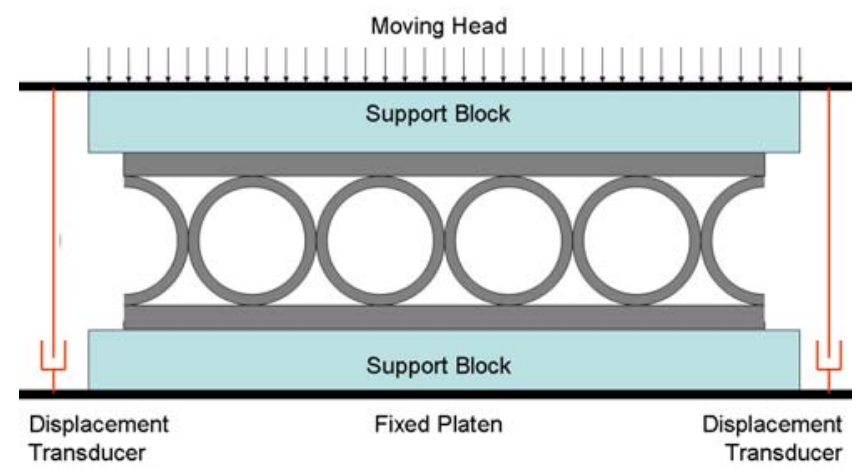

Figure 2. Schematic Test Setup for Crush Test

Displacements were measured via two string potentiometers mounted between the fixed and movable heads of the universal testing machine. Applied load was recorded via load cell in the movable head of the machine. Video cameras were positioned to record two views of the crush tests as they progressed.

\section{Characteristic Deformation Modes}

Each core geometry exhibited a unique load-displacement characteristic and crushing mode shape. For each of the three core geometries examined, the load-displacement results were fairly repeatable from test article to test article. Additionally, the characteristic crushing behavior was similar for pipe cores of the same diameter, and for the diamond cores. These results are discussed below for the three categories of core geometries: $\mathrm{X}$-core, diamond core, and pipe core.

For the X-core geometry, a total of four test articles were constructed and tested. The geometry was the same for each sample, but different methods of welding were used to assemble each panel. Each panel was approximately 5" high. As can be seen in Figure 3, the characteristic load-displacement behavior is similar for all panels. The $\mathrm{X}$-cores begin to crush with a relatively high force that peaks after approximately $1 / 2$ " of crush. The load then drops as plastic hinges begin to form in the legs of the cores. As the legs of the cores deform significantly, they begin to contact one another and the force required to further crush begins to increase. Eventually, the core material has experienced sufficient solidification to cause the load to increase nearly vertically with small increases in displacement.

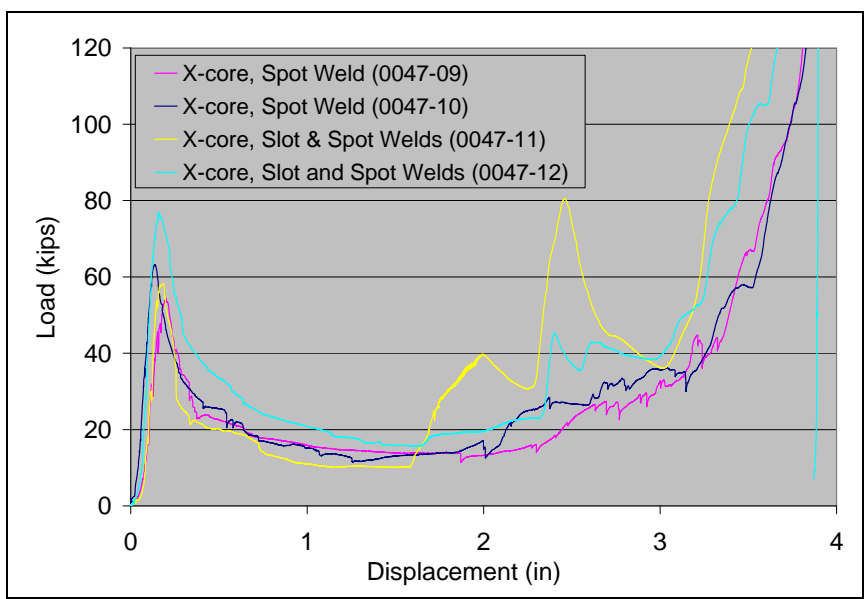

Figure 3. Load-displacement Results for X-cores, Crush Test

The crush tests performed on the X-cores exhibited the least repeatability in terms of mode shape of the crushed sample. As seen in Figure 4, each X-core within a given sandwich panel demonstrated a unique failure mode. Additionally, a number of $\mathrm{X}$-core panels experienced failed spot welds either between cores or between the core and the facesheet. 

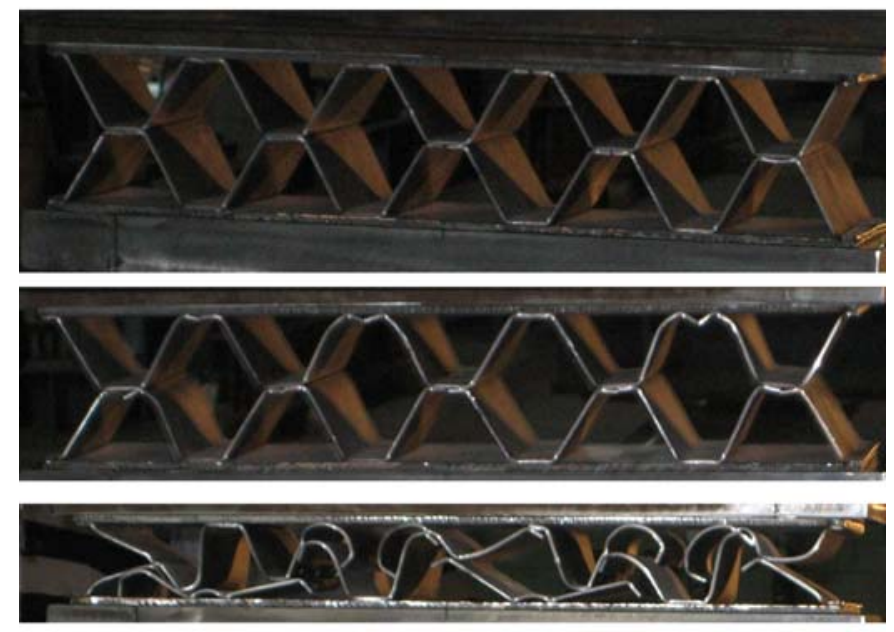

Figure 4. Progressive Crush of X-core Sample

Two sandwich panels were constructed using 2" square tubes rotated 45 degrees to form diamond-shaped cores. In one of these two panels, adjacent diamonds were stitch-welded to one another at the 3- and 9- o'clock positions. For both diamond panels, the load-displacement results are plotted in Figure 5. Both panels exhibited an initially high peak force of nearly the same magnitude.

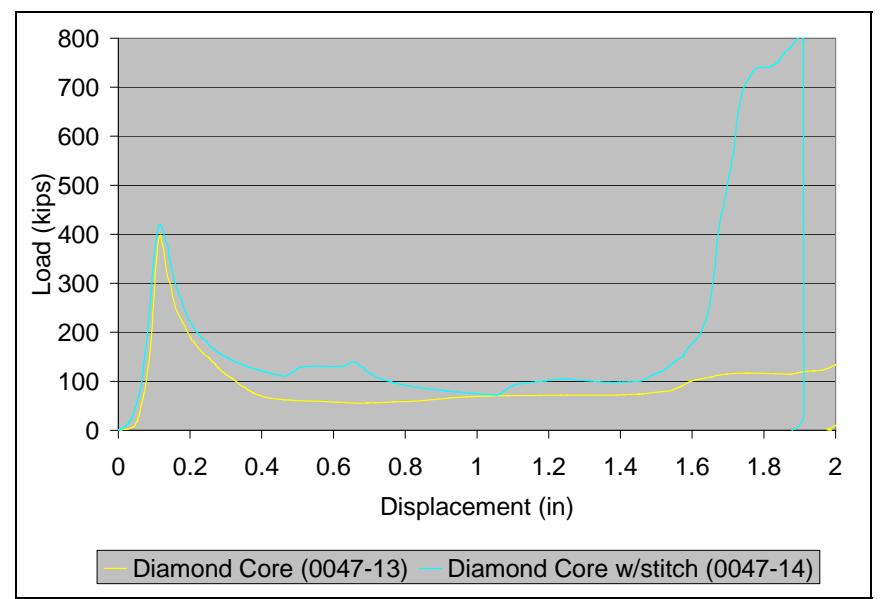

Figure 5. Load-displacement Results for Diamond Cores, Crush Test

As each core was compressed vertically, it attempted to expand laterally. However, the adjacent cores were also trying to expand laterally, causing the cores to "lock" together. Eventually, plastic deformation would occur in one or more legs of the cores, and the force level would drop. The force level would remain low until the cores were sufficiently compacted to form an effectively solid core to the sandwich panel, and the force would increase dramatically. Progressive crush of a diamond core sample is shown in Figure 6
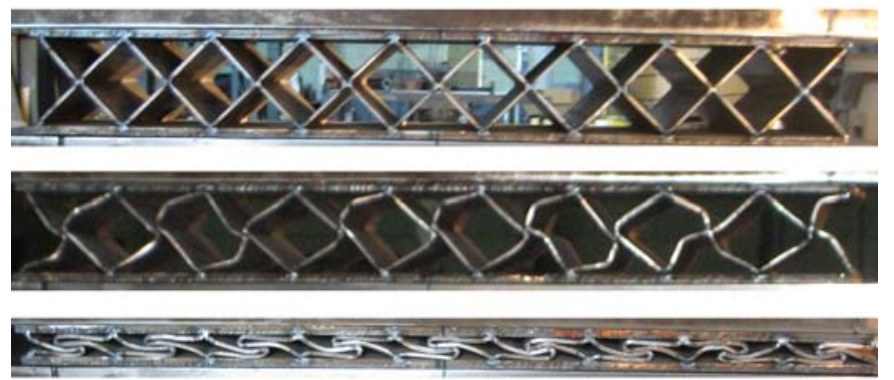

Figure 6. Progressive Crush on Diamond Core Sample

A total of eight panels were constructed using round cores. There were three sizes of core used: 2" diameter, 3" diameter, and 5" diameter. Two samples of each size were fabricated. Two additional panels were constructed using 2" pipes that were then stitch welded together at their 3- and 9-o'clock positions. The load-displacement characteristics for all eight round core panels are shown in Figure 7.

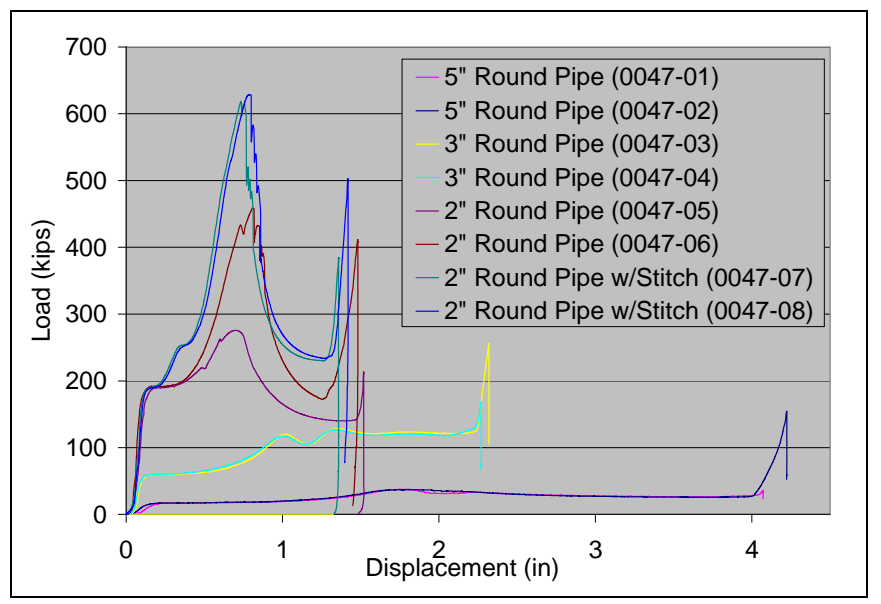

Figure 7. Load-displacement Results for Tube Cores, Crush Test

The characteristic crushing behavior of the round cores is different from either the $\mathrm{X}$-core or the diamond core panels. Where those configurations featured an initial high peak force the round cores all exhibit a rise in force followed by a gradually-increasing force plateau. Following this plateau, the cores exhibit a steeper rise in force and a peak crushing force. Once overcoming the peak the force drops, until the core has solidified. At that point, the force increases dramatically, as the core is nearly a solid at this stage. A series of photographs from the crush test of one of the 3" diameter pipe core panels is shown in Figure 8 

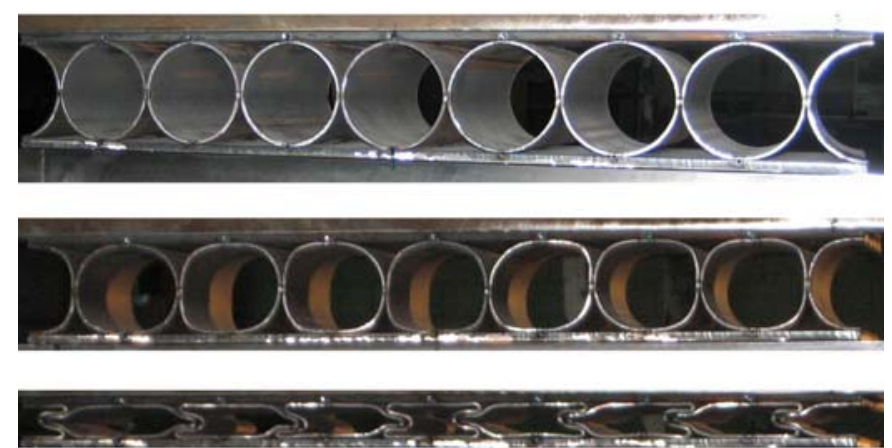

Figure 8. Progressive Crush on Tube Core Sample

The load-displacement plots in Figure 7 indicate three distinct groups of data. The lowest two load-displacement plots correspond to the 5" tubes, the middle two series are the data from the 3" diameter tubes, and the highest series correspond to the 2" diameter tubes. As the diameter of the tube decreases, the force levels to crush the tubes increase.

Regardless of the diameter of the tubes, the mechanism by which the tubes fail is the same. As the load is applied, the tube is squeezed at the top and the bottom. Each tube attempts to deform outward at the 3- and 9-o'clock positions, but is met with resistance from the adjacent tube. Because the panels were constructed with the tubes in close proximity to one another, the tubes contact one another nearly immediately once crushing has begun. The tubes then begin to square off, forming 8 plastic hinges around their circumference. These plastic hinges were predicted for tubes with internal bracing; the presence of adjacent tubes restricts the mode of deformation in much the same way as internal bracing would [4]. Because the larger diameter tubes have a larger moment arm between the applied loads and the hinge locations, a smaller force is required to initiate plastic hinge formation, given that all tubes used 0.125 ” steel of the same type.

During crush of the 2" diameter tubes, large lateral deflections were observed in all test samples. Because the tube wall thickness was maintained at 0.125 ” for all diameters of tubes, this resulted in a higher core density as the diameter of the tube was decreased. From Figure 7, the loads required to crush the 2" cores were much higher than the loads required to crush any other core examined. For all other cores, friction between the support blocks in the testing machine and the facesheets was sufficient to prevent lateral motion of the test article. However, due to the high applied loads and the formation of plastic hinges, the 2" tube core sandwich panel was able to overcome friction and shift laterally. This behavior was observed in all four 2" sandwich panels, and is shown in Figure 9.

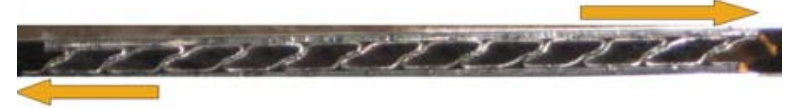

Figure 9. Deformed Shape of 2" Tube Core Showing Relative Motion of Facesheets

\section{Finite Element Analysis Results}

Overall, the pre-test finite element analyses predicted modes of deformation of the panels that were consistent with what was seen in the testing. Additionally, the pre-test finite element models generated load-displacement characteristics that were qualitatively similar to the results recorded in the test. However, finite element analysis results nearly universally over-predicted the force levels experienced by the panels in the test. Figure 10 shows test results for 5" pipe panels and the finite element model of the panels. As this figure shows, the finite element results follow the same trend as both sets of test data, with peaks occurring at approximately the same levels of displacement. However, the finite element model over-predicts the force necessary to crush the panel at all levels of displacement.

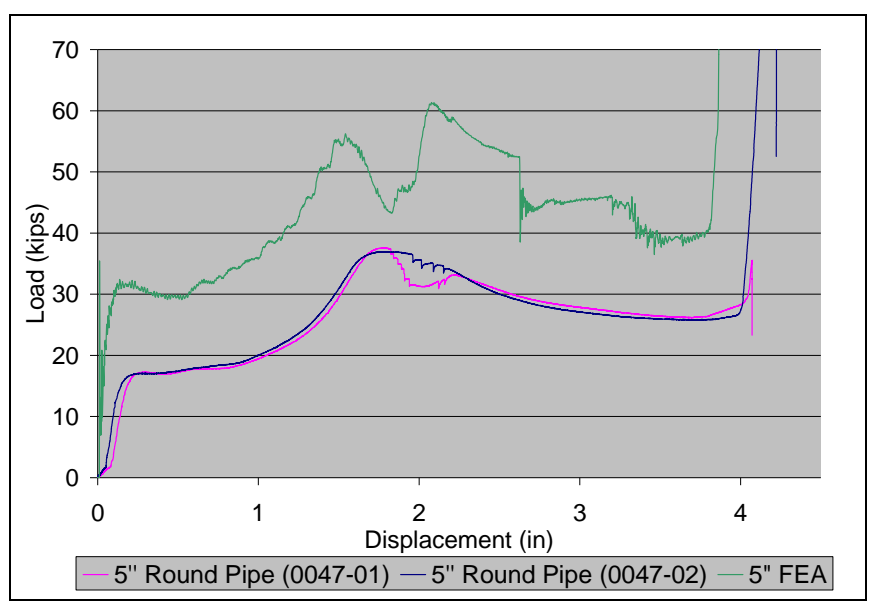

Figure 10. Example Force-displacement Results from Crush Test

This tendency to capture the qualitative behavior of the panels while over-predicting the actual force level may be attributed to the perfect geometry and lack of residual stresses incorporated in the FE model. In reality, the tubes used to make up the cores of the sandwich panels retain some residual stresses from their manufacture, as well as small imperfections in material. This allows collapse of the tubes to occur at a lower load than predicted by the FE model.

Figure 11 shows a comparison between the deformed shape at an intermediate point during the crushing of a 3" round core sample. The top half of this figure contains a photograph of the actual test article, while the bottom half contains an image from a finite element analysis. The two images demonstrate that the FEA is adequately capturing the deformation mode of the sandwich panel for this load case. In general, the FE model results accurately described the mode shape experienced by the corresponding panel during testing. 

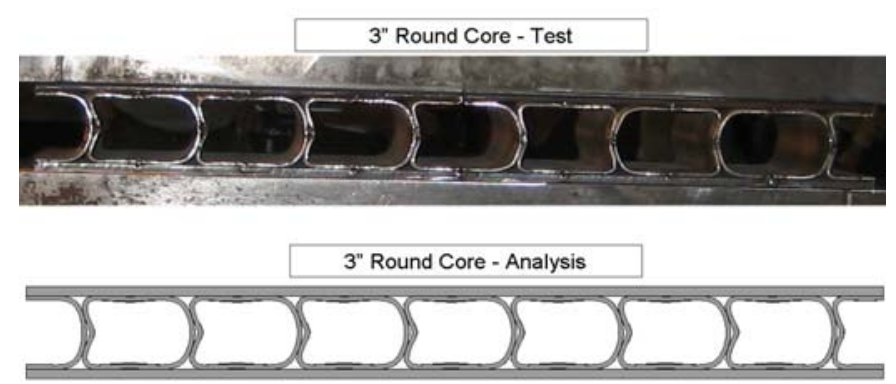

Figure 11. Comparison Between Deformed Shapes in Test and Analysis for 3” Round Core

\section{TEST 2 - 3 POINT BENDING}

The second test to be performed in this series was a 3-point bending test of a group of sandwich panels. This test series was designed to examine loading where the anticipated failure mode would result in large deformation of the facesheets, not solely crush of the cores. Based partially on the results of the first test, the field of possible cores was narrowed. The X-core geometry was eliminated from this test series due to the overall poor performance of the welds of the X-core in the first test, as well as the relatively low crush force offered by the $\mathrm{X}$ cores once the initial peak was overcome. The 5-inch pipes were eliminated due to their low crush force as well. The 2-inch pipes were eliminated from further testing due to the amount of welding necessary to assemble a panel made up of such small pipes. Additionally, because of the difficult-to-predict lateral shift in the 2-inch pipe panels these panels were eliminated.

The remaining configurations that were tested in the second test were a 3-inch outer diameter round tube and a 2-inch square diamond. These two cores were selected based on their performance in the first test as well as their relative ease of manufacture A total of 16 panels were built and tested in bending. The panels all measured approximately 48” in width by 18” in depth. The test articles are described in Table 3.
Table 3. Test Articles for Bending Test

\begin{tabular}{|c|c|c|c|c|}
\hline $\begin{array}{c}\text { Panel } \\
\text { No. }\end{array}$ & Core Type & $\begin{array}{c}\text { Core } \\
\text { Orientation }\end{array}$ & Facesheet Type & $\begin{array}{c}\text { Weight } \\
\text { (lbs) }\end{array}$ \\
\hline $0047-15$ & Diamond & Parallel & Solid & 139.5 \\
\hline $0047-16$ & Diamond & Parallel & Solid & 139.5 \\
\hline $0044-17$ & Diamond & Perpendicular & Solid & 140 \\
\hline $0047-18$ & Diamond & Perpendicular & Solid & 137 \\
\hline $0047-19$ & 3-inch Pipe & Parallel & Solid & 139.5 \\
\hline $0047-20$ & 3-inch Pipe & Parallel & Solid & 139.5 \\
\hline $0047-21$ & 3-inch Pipe & Perpendicular & Solid & 141 \\
\hline $0047-22$ & 3-inch Pipe & Perpendicular & Solid & 142.5 \\
\hline $0047-23$ & Diamond & Perpendicular & Strip & 109.5 \\
\hline $0047-24$ & Diamond & Parallel & Strip & 111.5 \\
\hline $0047-25$ & 3-inch Pipe & Perpendicular & Strip & 110.5 \\
\hline $0047-26$ & 3-inch Pipe & Parallel & Strip & 111 \\
\hline $0047-27$ & Diamond & Perpendicular & Strip & 137 \\
\hline $0047-28$ & Diamond & Parallel & Strip & 109 \\
\hline $0047-29$ & Diamond & Perpendicular & Solid \& Strip & 126 \\
\hline $0047-30$ & Diamond & Perpendicular & Solid \& Strip & 126 \\
\hline
\end{tabular}

A simple 3-point bending test setup was used for this test. As shown schematically in Figure 12, the sandwich panel was supported by two 4-inch diameter round steel bars placed 24 inches apart. These bars were welded to a thick steel plate, which was placed on the fixed head of the universal testing machine. Load was applied through a 12-inch x 12-inch load head with 1-inch radius rounded corners. This load head was mounted on the movable head of the universal testing machine. The load head was centered on the sandwich panel in both the width and depth dimensions.

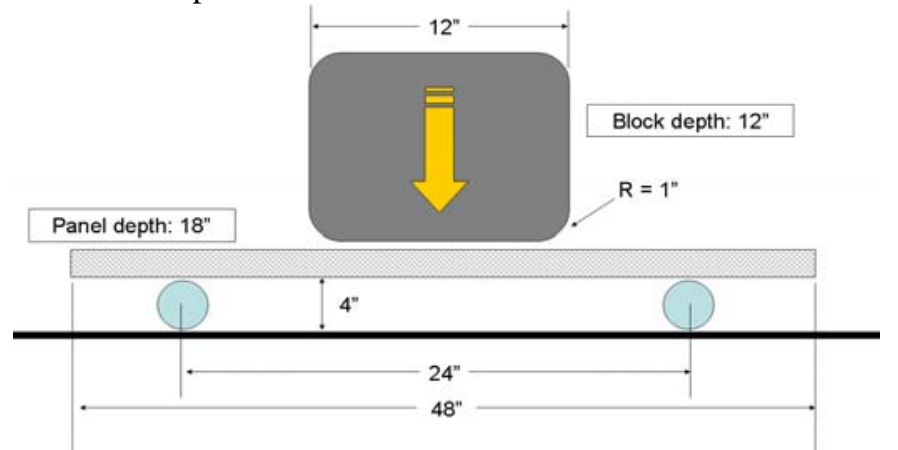

Figure 12. Schematic Test Setup for Bending Test

Test articles were constructed with cores oriented either perpendicular or parallel to the direction of the supports. This was done to examine the performance of the different cores with respect to orientation on a tank, which exhibits anisotropic bending stiffness along its length versus around its circumference.

For the bending test, core thickness was maintained at approximately 0.125 inches for the diamonds and for the tubes. 
Both cores were made of AISI 1010 steel. The facesheets were made of 0.125-inch Domex steel. The thinner facesheets were chosen to save weight in the panels as well as to decrease the likelihood of localized tearing of the facesheets due to facesheets that were overly stiff.

One concern with the sandwich panel approach to preventing tank car puncture is the possibility of a localized tear in the facesheet spreading along the perimeter of the impacting object. If this occurs, the impacting object may locally tear through the sandwich structure without engaging the structure outside of the impact area. This ability to "short circuit" the benefits of the sandwich panel on tank car protection is highly undesirable.

As a measure for preventing the propagation of cracks in the facesheets, the use of strip facesheets was suggested for this test. Rather than using monolithic facesheets, as are typically used in sandwich panel construction, strips of material are used as facesheets on one or both sides of the sandwich panel. In the event of a crack forming in a facesheet, the crack is effectively arrested when it reaches the edge of a strip and cannot jump to another strip. In a monolithic facesheet, the crack could continue traveling across the width of the facesheet. Solid and strip facesheets are shown in Figure 13 for two sandwich panels with 3" tubes in parallel orientation. For any panel constructed using strip facesheets the pattern chosen was a 3-inch strip of material adjacent to a 3-inch gap with no facesheet.

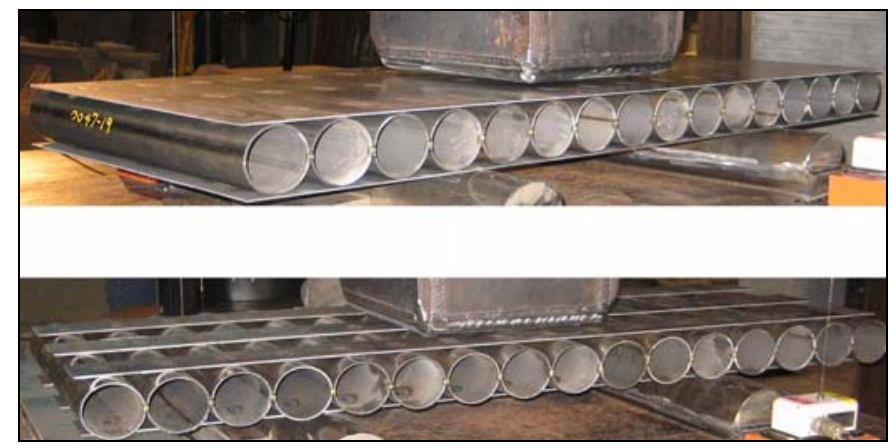

Figure 13. Pipe Core Sandwich Panel with Solid (top photo) and Strip (bottom photo) Facesheets

\section{Bending Behavior of Panels}

For all panels, the behavior under three point bending load can be divided into three general phases. These phases are shown schematically in Figure 14. In the first phase, the panel undergoes elastic bending. In the next phase, the panel is experiencing a localized buckling. This phase is characterized by a plateau or slight slope to the applied force. In the third phase, the bottom facesheet has come into contact with the fixed load head and the cores are experiencing crushing. The crushing behavior of the cores beneath the load head is similar to the behavior of the corresponding core configuration tested in uniaxial compression in Test 1.

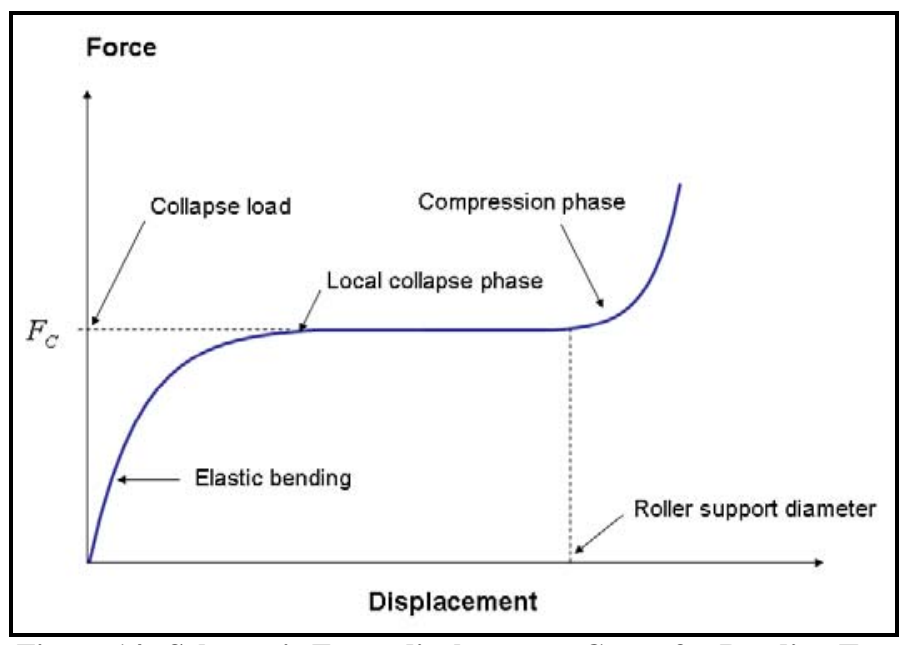

Figure 14. Schematic Force-displacement Curve for Bending Test

\section{Core Orientation}

For both the pipe core and the diamond core panels, trends emerged in the behavior of the panels during the bend testing. Regardless of the core geometry, panels built with cores oriented perpendicular to the supports required a larger force to deform than a panel with the same core oriented parallel to the supports. For the panels with cores oriented perpendicular, the entire panel resists bending from the first contact of the rigid block. For panels with the cores parallel to the supports, the cores are free to move past one another, and only the facesheets provide the initial bending strength. Example loaddisplacement characteristics are shown in Figure 15 for pipe core panels with strip facesheets. The results from cores oriented parallel to the supports are plotted alongside results from cores perpendicular to the supports. The perpendicular cores require more force to bend than the parallel cores. Finite element analysis results are plotted for both core orientations and show good agreement with the test data.

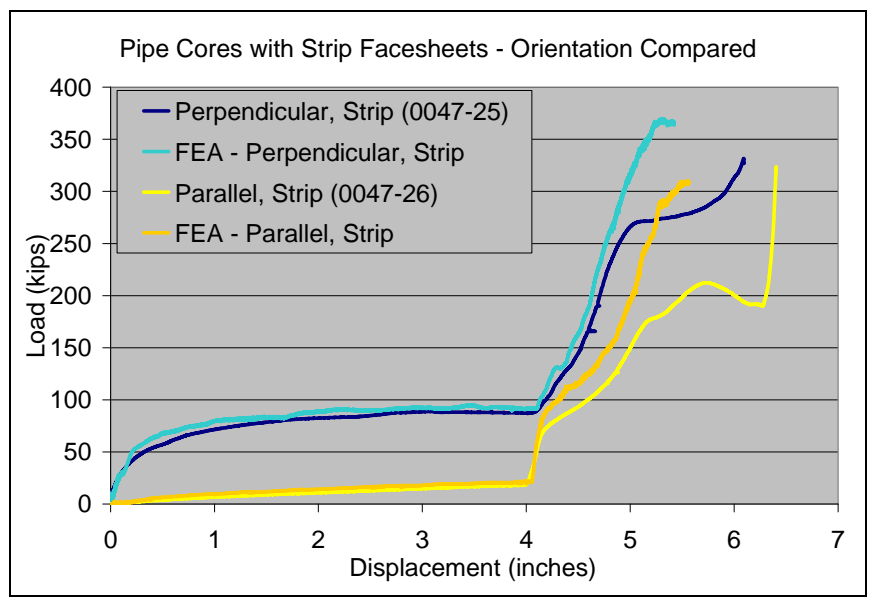

Figure 15. Load-displacement Behavior for Pipe Cores with Different Core Orientations

As seen in Figure 15, finite element analysis results compare favorably with the test results for each compared panel. 
Because of the bending test setup, during the first four inches of displacement the panel is in bending. After that displacement the bottom facesheet has contacted the supporting structure and crush of the cores occurs. Finite element results compare more favorably in the bending phase of the test than in the compression phase, where the analysis tends to over-predict the response. Based on the results of the bending and crush tests and the corresponding analyses, it appears that crush of the cores is more sensitive to small imperfections and residual stresses than bending of the panels.

\section{Pipe and Diamond Core Behavior}

Panels with at least one strip facesheet were constructed using pipe core and using diamond cores. Regardless of the core geometry, panels with solid facesheets were stiffer than panels with strip facesheets. The solid facesheet offers more resistance to bending than the strip facesheets, which cannot transfer bending loads from one strip to another.

Figure 16 is a load-displacement characteristic plot for perpendicular-oriented panels with solid facesheets. This figure contains data from diamond and pipe core tests. These results are selected for discussion because the load cases with solid facesheets and perpendicularly-oriented cores are the stiffest panels relative to any other configuration tested. The diamondcore panels had a more uniform bending strength than the pipe cores, which reached a local maximum and dropped off before contacting the bottom load head.

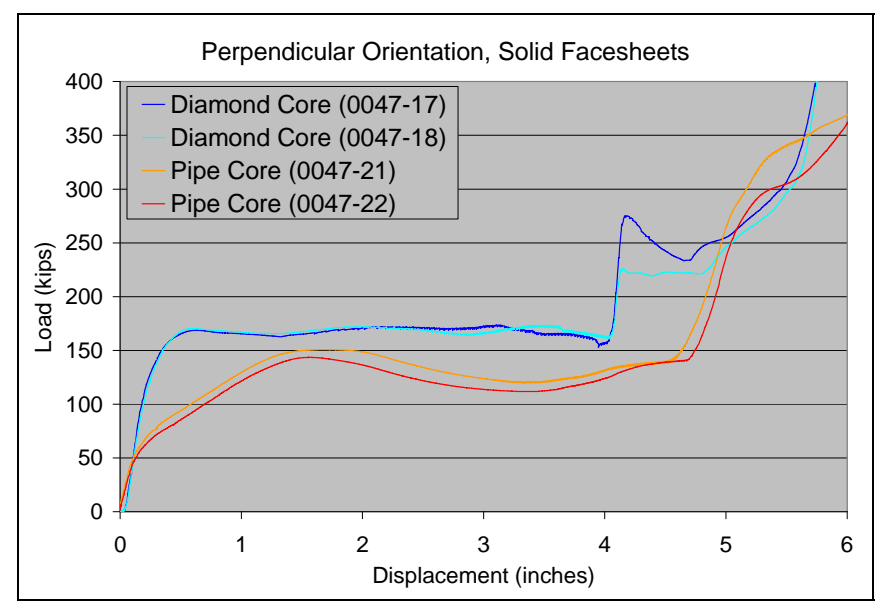

Figure 16. Load-displacement Characteristics for Panels with Perpendicular Orientation and Solid Facesheets

During the test, localized crushing of the cores was observed on the pipe-core panels at three locations: beneath the load head and above each of the two supports. During the tests of the diamond-core panels, no such localized crush was observed at the supports. Figure 17 indicates the deformation in the top photo of the pipe core sample alongside a diamond core photo where no such deformations are observable.
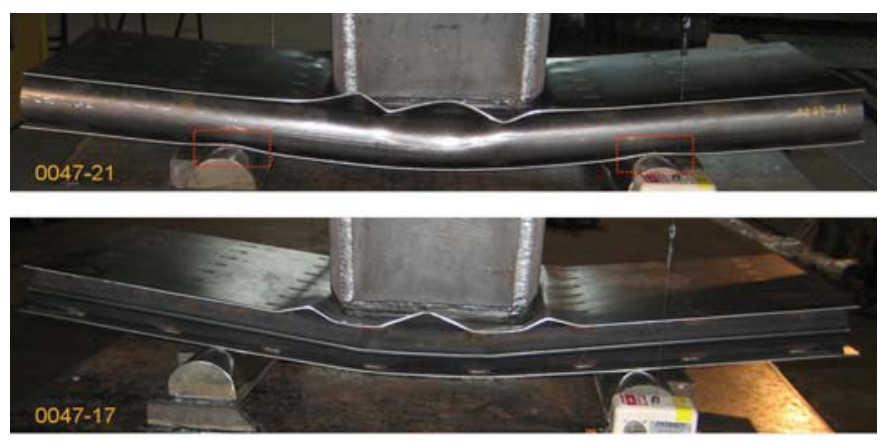

Figure 17. Localized Indentation in Pipe Core (top) and Absence of Indentation in Diamond Core (bottom)

During a bending test of a sandwich panel, competing modes of deformation are possible for panels of different designs. Results from the bending test are compared to results for the crush test of the diamond cores in Figure 18. In this plot, the initial peak crush strength of the diamond cores far exceeds the initial bending load of the diamond panel. Because of this, the panel is more likely to experience gross bending until contacting the bottom load head, at which point crushing will occur.

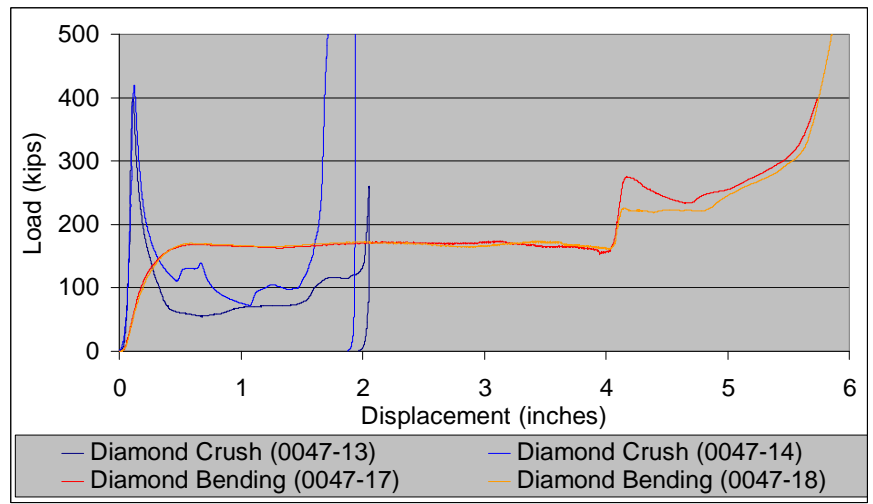

Figure 18. Diamond Core Load-displacement Behavior from Compression Test and Bending Test

A similar plot is shown for the 3-inch diameter tube cores in Figure 19. Because the tubes do not have an initial high peak crush load, the deformation mode is less clear-cut. In the crush test, the pipe cores experience a relatively steady crushing load as the result of plastic hinge formation and spreading. From the results of the bending test, the panel appears to simultaneously experience crush of the cores under the load head and the two supports as well as gross bending of the panel. 


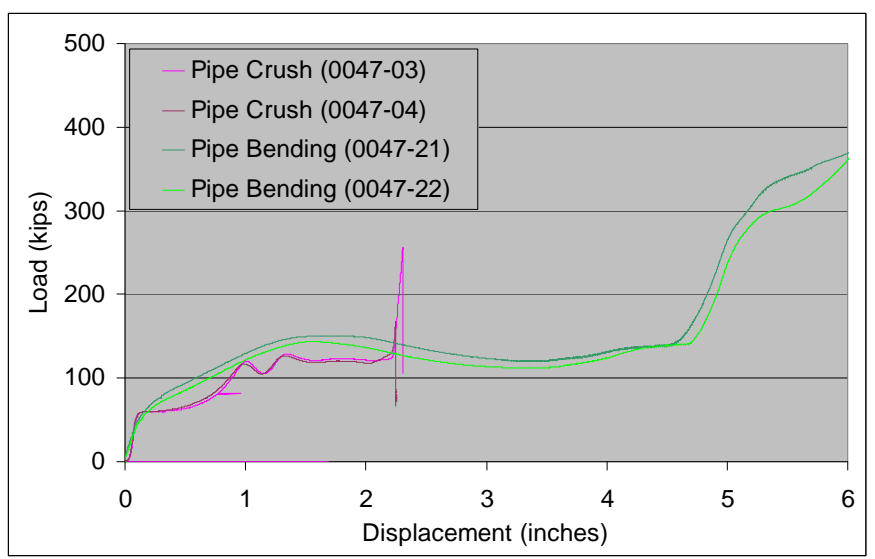

Figure 19. Pipe Core Load-displacement Behavior from Compression Test and Bending Test

\section{Solid Facesheets and Strip Facesheets}

Figure 20 shows the load-displacement characteristics for four tests and two analyses of panels with parallel-oriented diamond cores. Two panels tested featured solid facesheets and two panels featured strip facesheets. For either facesheet configuration, the two panels demonstrated similar loaddisplacement behavior. Additionally, the finite element predictions matched the overall shape of the test results and closely matched the peak crush force for both panel configurations.

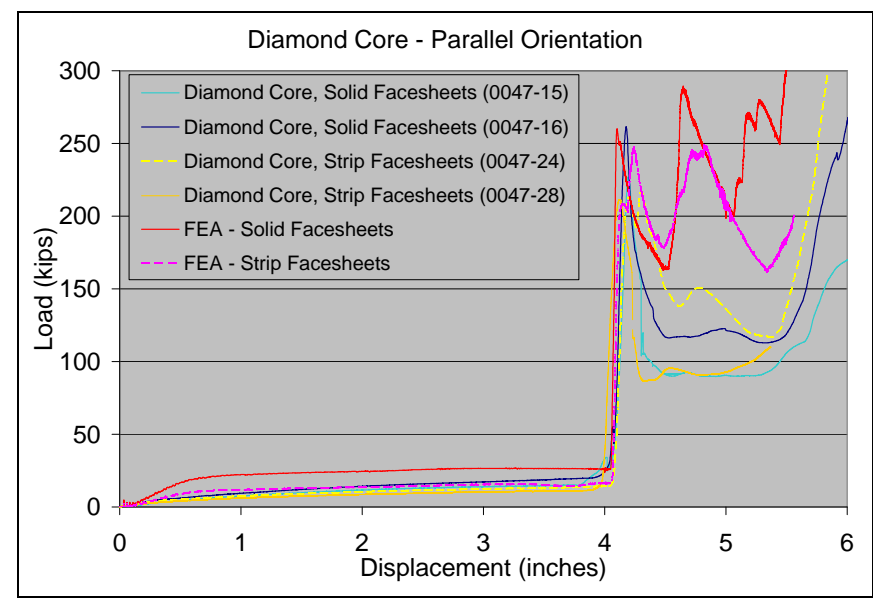

Figure 20. Load-displacement Results for Parallel Diamond Cores

The panels with strip facesheets resulted in lower forces to deform the panel a given distance than the solid facesheets. This is due to the loss of bending stiffness associated with the discontinuous facesheets on the strip panels. The crush strength of the cores is slightly reduced in the panels with the strip facesheets, likely due to the increased ability for the cores to deform without contacting facesheets in the gap spaces.

One of the reasons for selection of strip facesheets as candidates for tank protection was the ability of the strips to prevent cracks from propagating through the facesheet and causing localized fracture of the sandwich panel. During testing, crack propagation was observed in two diamond-core panels, 0047-17 and 0047-18. Both of these panels featured cores oriented perpendicular to the supports, which results in a stiffer panel than cores oriented parallel to the supports. In both panels, cracks formed in the inner facesheet in the area around the welds in the center of the panel. These cracks are indicated in Figure 21.
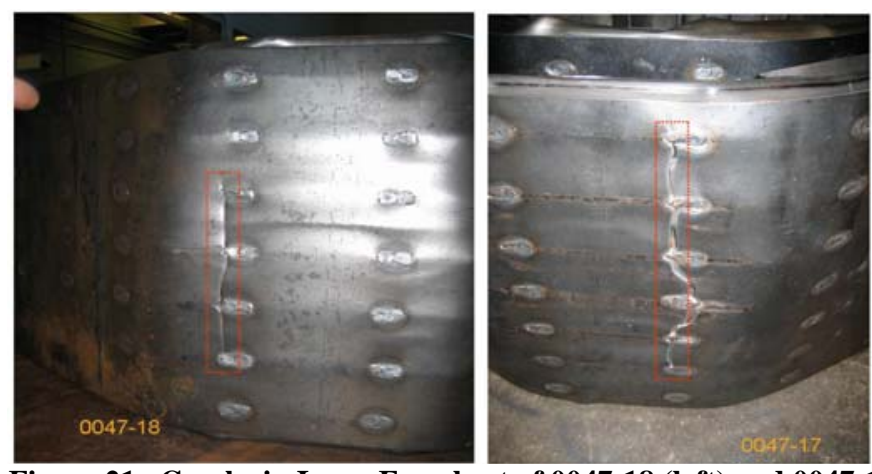

Figure 21. Cracks in Inner Facesheet of 0047-18 (left) and 0047-17 (right)

Four additional panels with perpendicularly-oriented diamond cores were tested in bending. Two of these panels featured strip facesheets on both the top and bottom, and two of these panels featured a solid facesheet on one side and a strip facesheet on the other. Of the two "hybrid" panels with one solid and one strip facesheet, one was tested with the solid facesheet facing up, and one was tested with the strip facesheet facing up. Load-displacement characteristics are plotted for all six sandwich panels with perpendicular-oriented diamond cores in Figure 22

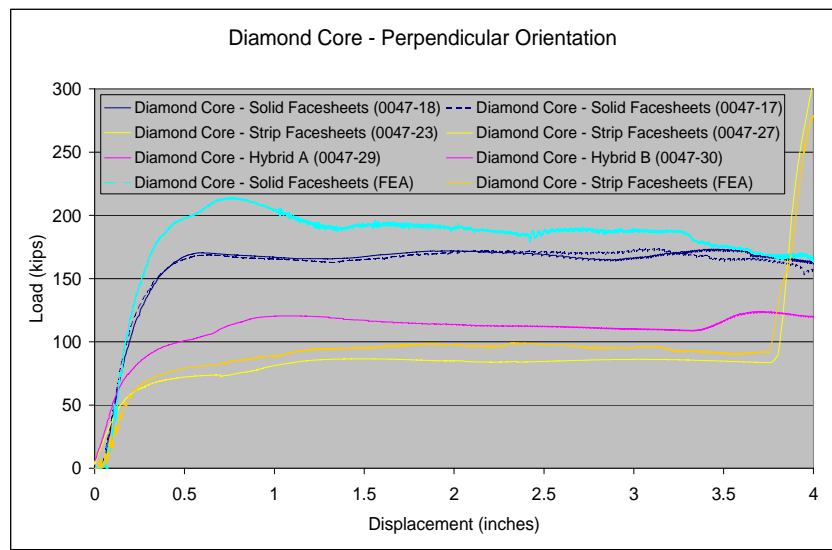

Figure 22. Load-displacement Behavior for Perpendicularlyorientation Diamond Core Panels

Of the diamond core panels with perpendicular orientation, only the two panels with both solid facesheets experienced the crack propagation shown in Figure 21. For all of the additional diamond core panels with at least one strip facesheet the facesheets did not crack. This gives an indication that the strip facesheets allow greater flexibility in the deformation of the 
panel, preventing the large tensile forces that caused tearing of the facesheets.

\section{Measurement of Relative Contact Area}

One of the positive attributes associated with sandwich panels is the ability to blunt an impact load, making the impacting object appear to have a larger footprint when it comes into contact with the supporting structure. In the case of a tank car, this supporting structure is the commodity tank. For a given impact speed and impact mass, the amount of energy needed to puncture a tank of given thickness increases with the size of the impacting object [5].

As a part of this series of bending tests it was desirable to attempt to quantify the amount of blunting, or load spreading, that the sandwich panels affected on the impactor. A low-cost method for measuring the contact area on the fixed platen was implemented for a small number of bending tests. A sheet of commercially-available bubble wrap was placed on the fixed platen in the area between the two supports, as shown in Figure 23. When the inner facesheet of the sandwich panel began to contact the bubble wrap, the increasing force level would pop the bubbles. After the test was completed, the popped bubbles could be examined and the contact area could be determined.

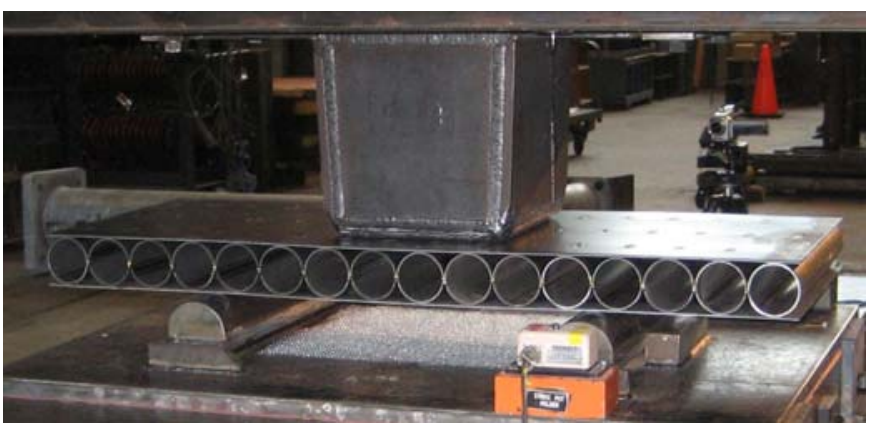

Figure 23. Bending Test Setup with Bubble Wrap to Indicate Contact

The bubble wrap method was used in two test cases. In one, a panel with parallel-oriented pipe cores and solid facesheets had an inner platen contact area of 16 inches in the direction of the supports by 14.5 inches wide. In the second test, a panel with parallel-oriented diamond cores and solid facesheets had an inner platen contact area of 16 inches in the direction of the supports by 13.25 inches wide. The particular bubble wrap used in this test had a total sheet width of 16 inches, limiting the measurable range in the direction parallel to the supports.

In both cases, the sandwich panel demonstrated its ability to increase the loaded area of the impactor alone. Because of the rounded corners of the impactor, the area initially in contact with the outer facesheet is 10 inches by 10 inches. During the deformation of the panel, the full 12 inch by 12 inch impactor contacts the outer facesheet. Using the 12 inch by 12 inch dimension as the baseline contact area, the area of contact reported by the bubble wrap for both tests is approximately 50 percent greater.

\section{CONCLUDING DISCUSSION}

Compression tests were conducted on five sandwich panel geometries: 2-inch, 3-inch, and 5-inch pipe cores, diamond cores, and X-cores. Based on the results of these compression tests, 3-inch pipe cores and diamond cores were selected for additional examination in the form of 3-point bending tests. Bending tests were conducted to examine the effect of the two core geometries, as well as the influence of core orientation on bending behavior, the effectiveness of strip facesheets at inhibiting facesheet tearing, and the load-spreading benefits of the panels.

The purpose of investigating sandwich panels is to develop effective strategies for enhancing the impact resistance of tank cars carrying hazardous materials. It is envisioned that the sandwich panels would be utilized as a protective outer covering for the tank car, in place of the conventional jacket. Further studies are ongoing investigating the behavior of steel panels used as protective structures surrounding commodity tanks.

\section{ACKNOWLEDGMENTS}

The work described in this paper was sponsored by the Federal Railroad Administration, Office of Research and Development. Mr. Kevin Kesler is the Chief of the Equipment and Operating Practices Division.

Cellular Materials International (CMI) constructed the panels used in both tests. Dr. Yellapu Murty, Mr. Bob Kurtz, and Mr. Kerry Elzey have been heavily involved in discussing and implementing the design and fabrication of the steel panels used in this research effort.

\section{REFERENCES}

1. Tyrell, D.C., Jacobsen, K., Talamini, B., Carolan, M., "Developing Strategies for Maintaining Tank Car Integrity During Train Accidents," Proceedings of the 2007 ASME Rail Transportation Division Fall Technical Conference, RTDF2007-46015, September 2007.

2. Carolan, M., Talamini, B., Tyrell, D.C., (2008). "Update on Ongoing Tank Car Crashworthiness Research: Predicted Performance and Fabrication Approach," Proceedings of the 2008 IEEE/ASME Joint Rail Conference, JRC2008-63052.

3. Tang, Y.H., Yu, H., Gordon, J.E., Priante, M., Jeong, D.Y., Tyrell, D.C., Perlman, A.B., "Analysis of Full-Scale Tank Car Shell Impact Tests," Proceedings of the 2007 ASME Rail Transportation Division Fall Technical Conference, RTDF2007-46010, September 2007. 
4. She, M., and Carney, J. "Energy Dissipation Properties of Metallic, Cellular, and Composite Structures.” Vanderbilt Engineering Center for Transportation Operations and Research. August, 1994.

5. Tang, Y.H., Yu, H., Gordon, J.E., Jeong, D.Y., Perlman, A.B., "Analysis of Railroad Tank Car Shell Impacts Using Finite Element Method," Proceedings of the 2008 IEEE/ASME Joint Rail Conference, JRC2008-63014, April 2008.

6. Abaqus 6.10-1. Providence, RI. Dassault Systèmes, 2010. 